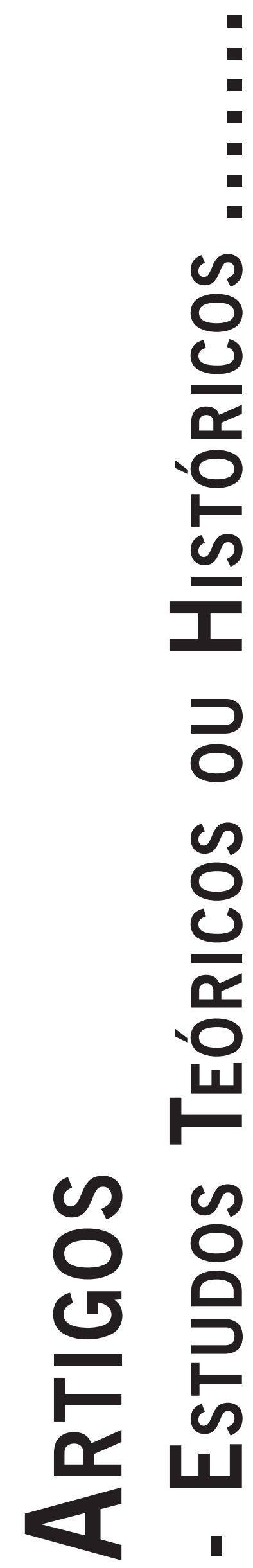




\title{
ENCONTRANDO UM MODO DE SER ESQUIZOFRÊNICO: ARTE E TÉCNICA NA GESTALT-TERAPIA
}

\author{
Meeting a schizophrenic way of being: art and technique in Gestalt-therapy \\ Encontrando uma manera de ser esquizofrénica: arte y técnica en la Terapia Gestalt \\ Júlio Manoel dos Santos Filho \\ Virgínia Elizabeth Suassuna Martins Costa
}

\begin{abstract}
Resumo: A esquizofrenia é considerada, tradicionalmente, um transtorno mental que envolve a presença de sintomas psicóticos: comportamentos incomuns tais como delírios e alucinações. Na percepção da Gestalt-terapia, referencial teórico deste trabalho, a esquizofrenia, tal como qualquer outra psicopatologia, é compreendida enquanto uma tentativa de diálogo que foi abortada. Assim, abrir espaço para que haja continuidade nesse diálogo é o mesmo que promover saúde. Com este intento, é utilizada neste estudo a perspectiva fenomenológica. Partindo desse modo de ação e dos referenciais teóricos da Gestalt-terapia, busca-se apresentar modos pelos quais o encontro pode auxiliar na promoção da saúde existencial. No caso aqui apresentado, o contato com a própria experiência, estimulado na psicoterapia, faz com que o cliente apresente novos conteúdos existenciais.
\end{abstract}

Palavras-chave: Encontro; Esquizofrenia; Fenomenologia; Gestalt-terapia.

\begin{abstract}
The schizophrenia is traditionally considered a mental disorder that involves the presence of psychotic symptoms: unusual behaviors as delusions and hallucinations. In Gestalt-therapy comprehension, schizophrenia as others psychopathologies, is considered a dialogue attempt which was aborted. So, enabling dialogue continuity results in existential health promotion. Seeking a demonstration about how the therapeutic meeting can help to promote the existential health, this study uses the phenomenological perspective and the Gestalt-therapy theoretical references. In the case presented in this paper, it is shown that the own experience contact encouraged in psychotherapy enables the client's new existential contents flux.
\end{abstract}

Keywords: Meeting; Schizophrenia; Phenomenology; Gestalt-therapy.

Resumen: La esquizofrenia se considera tradicionalmente un trastorno mental que implica la presencia de síntomas psicóticos: comportamientos inusuales como delirios y alucinaciones. En la comprensión de la terapia Gestalt, la esquizofrenia como otras psicopatologías, se considera un intento de diálogo que fue abortada. Así, lo que permite la continuidad del diálogo resulta en promoción de la salud existencial. Buscando una demostración acerca de cómo el encuentro terapéutico puede ayudar a promover la salud existencial, este estudio utiliza la perspectiva fenomenológica y la Gestalt-terapia referencias teóricas. En el caso presentado en este trabajo, se demuestra que la propia experiencia de contacto alentado en psicoterapia permite nuevo flujo de contenidos existenciales del cliente.

Palabras-clave: Encuentro; Esquizofrenia; Fenomenologia; Terapia Gestalt.

\section{Introdução}

O encontro pode ser entendido como uma arte, assim como a própria Gestalt-terapia, que não aspira ao status de ciência, mas goza da honra de ser percebida como uma forma artística (Ginger \& Ginger, 1995). Aqui a arte é compreendida com uma capacidade especial, um dom para realizar uma tarefa específica (Feldman, 2006). Contudo, a subjetividade desta capacidade é perfeitamente conciliável com a objetividade da pesquisa e da sistematização (Feldman, 2006). Este par “objetividade/subjetividade” é uma habilidade necessária ao terapeuta, que é convidado a manter uma presença-distanciada, permanecendo presente e ao mesmo tempo refletindo a respeito do que está sendo experienciado (Hycner, 1995).

No que diz respeito à técnica, Fagan (1980) assinala que são tarefas do terapeuta a construção de padrões a respeito do comportamento do cliente, o controle na condução da psicoterapia e a aceleração do processo de mudança numa direção positiva. Ao mesmo tempo, esse autor aponta a necessidade do envolvimento pessoal e do comprometimento do terapeuta com sua própria vocação e as exigências decorrentes dela, que solicitam a utilização de todos os seus recursos pessoais. Portanto, casar arte e técnica é uma habilidade indispensável no trabalho do terapeuta, já que no seu fazer ele utiliza tanto o que sabe quanto o que é (Ginger \& Ginger, 1995).

O casamento em questão, ao contrário de interferir negativamente na arte do encontro, aumenta sua efetividade (Feldman, 2006), favorecendo a atitude denominada presença-distanciada, descrita por Hycner (1995). Esse empreendimento se torna possível desde que esteja sob a luz de uma perspectiva humanista (Feldman, 2006). O humanismo é uma corrente filosófica cujas origens estão 
no Renascimento, um período em que foi enfatizada a riqueza das possibilidades humanas, até então inexploradas (Ginger \& Ginger, 1995). A filosofia humanista dá ênfase aos interesses, potencialidades e faculdades pertencentes ao homem, sendo, assim, uma visão de mundo e da existência que tem como centro o ser humano (Feldman, 2006). Esse olhar filosófico é um dos pontos de apoio da Gestalt-terapia, uma forma de psicoterapia que se propõe a exercitar a valorização do humano (Cardella, 2002). O citado exercício se dá pela busca do que há de positivo na pessoa e pela ênfase à capacidade criativa em relação à própria existência, a qual acontece por meio do contato com o próprio potencial de vida, compreendido como sua força, saúde e beleza (Ribeiro, 1985).

Outro apoio filosófico da Gestalt-terapia, o existencialismo propõe uma percepção do homem na sua originalidade: a experiência individual é irredutível, única, seja ela objetiva ou subjetiva. Também a concretude do ser é valorizada quando a vivência concreta é vista com primazia sobre a abstração, já que, para o existencialismo, esta apenas precede a ação (Ginger \& Ginger, 1995). Igualmente é dada ênfase à vontade e à liberdade da pessoa, vivências que estão atreladas à consciência e à responsabilidade do indivíduo (Ribeiro, 1985).

Humanismo e existencialismo são duas correntes filosóficas complementares e que apresentam muitos pontos em comum. Um deles diz respeito à capacidade da pessoa de escolher e crescer rumo ao seu potencial máximo, sendo responsável por seu devir (Feldman, 2006). Na perspectiva humanista, esse ponto se sustenta na percepção de que a pessoa é uma valência positiva, considerada como centro do universo, com capacidades de autogestão e auto-regulação. No existencialismo a sustentação vem da visão de homem como um ser particular, singular e único no universo, capaz de, por meio da sua experiência de ser no mundo, compreender a si próprio, sendo o mais fiel intérprete de si mesmo (Ribeiro, 1985).

Com base em pressupostos existenciais-humanistas, cabe ao psicoterapeuta ajudar seu cliente na descoberta de suas potencialidades (Feldman, 2006). Isso significa uma tentativa de ampliação de tudo o que define e mantém o homem enquanto tal e o vincula aos outros seres humanos (Ribeiro, 1985). O auxílio pretendido pelo terapeuta torna-se possível por meio de um encontro pautado numa relação de igualdade (Feldman, 2006). Nessa relação, tanto terapeuta quanto cliente estão numa mesma condição: são seres humanos que existem no mundo e procuram compreender, experienciar, reavaliar e singularizar o significado do existir. Vistos nesse movimento de busca pela integridade humana, o qual advém do fortalecimento da capacidade do próprio sujeito em seguir rumo à harmonia, os elementos da díade terapêutica se relacionam de maneira paritária, o que é chamado encontro existencial (Ribeiro, 1985). Contudo, cabe a observação de que nesse relacionamento de igualdade existem papéis diferenciados, sendo do terapeuta a tarefa de cuidar da qualidade da relação.
Encontrar alguém é uma experiência de estar plenamente presente com este outro, tanto quanto possível, de forma que poucos objetivos estejam voltados para si mesmo. Uma pessoa encontra a outra ao entrar em profunda sintonia com ela, percebendo sua condição e descobrindo-a (Feldman, 2006). O encontro, no qual cada uma das partes envolvidas aprecia a alteridade e a totalidade da outra, simultaneamente, é denominado por Martin Buber de Experiência Eu-Tu (Hycner \& Jacobs, 1997).

Quando fundado na relação Eu-Tu, o encontro não tem nada por objeto, o outro não é experienciado, já que isso seria o próprio distanciamento do Tu: quem diz Tu não possui coisa alguma (...) apenas permanece em relação. Assim, a palavra-princípio Eu-Tu fundamenta o mundo da relação (Buber, 1974). E aqui é que ocorre a possibilidade de um diálogo verdadeiro: quando duas pessoas se dispõem a aceitar, valorizar e apreciar a alteridade de cada uma (Hycner, 1995).

Por outro lado, o homem também entra em contato com a superfície das coisas e as experiencia: o mundo como experiência corresponde à palavra-princípio Eu-Isso (Buber, 1974). A alternância entre as vivências dos tipos Eu-Tu e Eu-Isso é inerente aos relacionamentos humanos. Contudo, ao extrapolar os limites da atitude Eu-Isso, quando estamos suficientemente envolvidos e interessados pela outra pessoa, entramos no domínio do entre. Este é um fenômeno ontológico, uma possibilidade própria à existência humana, onde há a transcendência da noção de identidade normalmente conhecida. Na filosofia de Martin Buber, trata-se de um acontecimento que fala sobre a natureza dialógica, característica que define e revela o que há de único no ser humano como a capacidade e o desejo de estabelecer e manter relações significativas com as outras pessoas (Hycner, 1995).

Com base no pensamento buberiano, aqui especificamente numa perspectiva dialógica, somente ao visitarmos a esfera do inter-humano, que é sinônimo para o entre, torna-se possível haver um encontro que possibilite o processo de cura (Hycner, 1995; Hycner \& Jacobs, 1997).

Neste estudo a condução dos encontros se dá numa perspectiva fenomenológica. Petrelli (1999) afirma que a única abordagem possível para compreender a existência é a fenomenologia. Através da descrição rigorosa do fenômeno que se mostra, da maneira como ele acontece, essa abordagem busca captar a essência das coisas, o que possibilita ver a existência humana no que ela tem de mais original (Romero, 1997). Uma vez que essa descrição visa à compreensão de como um determinado fenômeno é vivido pela pessoa, chega-se ao significado por ela atribuído a esta vivência (Ribeiro, 1985). No caso do encontro com alguém que busca ajuda, o que ocupa o lugar central na descrição fenomenológica é aquilo que é central para a pessoa, não o que seria central para uma dada psicopatologia (Dusen, 1975). 
Contudo, para que a descrição fenomenológica seja efetiva no alcance da essência do fenômeno que se mostra, é preciso que haja a suspensão de qualquer juízo existente a priori, movimento esse que permite perceber a realidade tal como ela é (Ribeiro, 1985). Nesse sentido, Hycner (1995) afirma que o terapeuta só pode entrar verdadeiramente no mundo do seu cliente, estando de fato presente com ele, quando consegue colocar entre parênteses os seus próprios significados, vieses e preconceitos.

A partir da descrição do fenômeno que emerge no contexto terapêutico, possibilitada pela suspensão exercitada pelo terapeuta, se torna possível ao cliente perceber-se funcionando como um todo. Este é o processo de ampliação da consciência chamado awareness, que acontece sempre aqui-e-agora. (Yontef, 1998). Para Ribeiro (2006), awareness é o ato de estar consciente da própria consciência, de ir ao encontro da própria intencionalidade. Esta consciência extrapola o domínio intelectual, traduzindo-se numa transcendência na qual o ser se percebe como um todo integrado no universo.

A visão do ser humano em integração com o mundo está presente no aparato filosófico e metodológico da Gestalt-terapia que, para além das filosofias e metodologias, também foi e é influenciada por variadas teorias que lhe dão sustentação, permanecendo em transformação continuamente (Cardella, 2002). Em relação ao aporte teórico, Frederick Perls, em conjunto com Paul Goodman, Paul Weisz, Isadore From e Laura Perls, dentre outros, criou a Gestalt-terapia em 1951 (Yontef, 1998). Essa criação foi possível a partir da compreensão da Psicologia da Gestalt, iniciada por Max Wertheimer, em conjunto com Wolfgang Kohler e Kurt Koffka, em 1912 e de sua articulação a dois movimentos contemporâneos: a Teoria de Campo, de Kurt Lewin e a Teoria Holística, de Kurt Goldstein (Ginger \& Ginger, 1995; Ribeiro, 1985).

A respeito da Psicologia da Gestalt é importante citar que os pesquisadores desta teoria estudaram os mecanismos psicológicos e fisiológicos da percepção e as relações do organismo com seu meio. Estas foram entendidas de forma dialética: o aspecto do objeto depende das necessidades do sujeito e as necessidades do sujeito dependem do aspecto do objeto (Ginger \& Ginger, 1995). É também da Psicologia da Gestalt que decorre o conceito de figura e fundo, utilizado por Perls como um dos principais suportes na fundamentação da Gestalt-terapia (Ribeiro, 1985). Esse conceito sustenta a idéia de que todo campo perceptivo se diferencia em um fundo e em uma forma ou figura (Ginger \& Ginger, 1995). A figura está contida no fundo e é por ele revelada, não podendo ser compreendida como uma parte separada, mas apenas revelada pelo fundo (Ribeiro, 1985). Essa diferenciação entre figura e fundo é sempre transitória, visto que o fundo é uma fonte contínua na formação de novas figuras (Polster \& Polster, 2001).
Ademais, a idéia de figura e fundo não se restringe à percepção sensória: os psicólogos da gestalt apontaram os paralelismos existentes entre os domínios físico e psíquico, que obedecem a leis análogas (Ginger \& Ginger, 1995). Isto justifica o fato de Kurt Goldstein ter se apoiado sobre a lei de figura e fundo para buscar um modelo referencial adequado para tratar da natureza do homem (Lima, 2005). A fim de compreender esse homem, assim como aos demais seres vivos, Goldstein propôs o método holístico, no qual o organismo é entendido como um todo e não como a soma de partes isoladas (Lima, 2005). Ao considerar o homem como um organismo unificado, que funciona como uma unidade na qual não cabe a divisão corpo/mente tem-se, por conseguinte, que qualquer estímulo que atinja esse ser irá promover mudanças na sua totalidade (Lima, 2005; Perls, 1988).

Essas mudanças são expressas por formas padronizadas de resposta, chamadas performances, que visam à busca de equilíbrio do sistema como um todo. Dessa maneira as tarefas necessárias ao bom funcionamento do organismo fazem parte da sua dotação natural e são percebidas como prioridades para o indivíduo. Mas, à medida que ele se relaciona com o meio, suas necessidades são atualizadas; assim, quando o indivíduo consegue se atualizar através de suas performances, respeitando a sua natureza, pode-se dizer, de acordo com a Teoria Organísmica, que ele se autorregula (Lima, 2005). Autorregulação é considerada sinônimo de busca pela homeostase, um processo de manutenção do equilíbrio que é sempre dinâmico (Cardella, 2002; Perls, 1988).

Do fato de a pessoa se regular na relação com o meio, obtém-se uma resposta à ordinária pergunta feita em linguagem mecanicista: "o indivíduo cria o ambiente ou o ambiente cria o indivíduo?” Na Teoria de Campo, outra base teórica da Gestalt-terapia, não existe esta dicotomia. O campo indivíduo/ambiente se cria com a parte individual influenciando o campo e vice-versa (Yontef, 1998). Qualquer fenômeno observado nunca é uma realidade objetiva em si, mas uma inter-relação global entre o próprio fenômeno e seu meio momentâneo: tudo está ligado (Ginger \& Ginger, 1995). Assim, toda experiência humana deve ser compreendida como uma interação dentro do campo organismo-meio, já que o indivíduo não é um sistema fechado e só pode existir dentro de um campo que o contém (Delisle, 1999; Perls, 1988).

Dizer que entre indivíduo e ambiente há uma mútua influência significa afirmar que a relação entre ambos é dialética. Assim, é decorrente e reveladora de características do campo, que se mostra como uma teia sistemática de relacionamentos que existe de forma contínua no espaço e no tempo. (Yontef, 1998). Ao ver o campo como uma combinação no tempo e no espaço de estímulos diversos, infere-se que ele conduz a experiências cujos resultados não podem ser preditos a partir do conhecimento de cada estímulo (Ginger \& Ginger, 1995). 
Fazendo parte de um campo maior que o influencia e é por ele influenciado, o homem se vê na sua liberdade de construir o mundo, por meio da atribuição de significados. Neste processo, a pessoa também se percebe num paradoxo: ao mesmo tempo em que ela é abertura originária às suas múltiplas possibilidades, também está diante das limitações da concretude do existir. Isso se dá porque a presença concreta do ser é restrita a um único lugar, permitindo a ele fazer apenas uma coisa de cada vez (Forghieri, 2004).

Diante deste paradoxo, o homem necessita ter a capacidade de articular de forma eficiente a amplitude e as restrições do existir. Esta capacidade é chamada saúde existencial (Forghieri, 2004). O oposto, a doença, mostra-se quando a pessoa responde de forma inadequada à realidade, colocando em perigo sua própria sobrevivência (Augras, 2004). O indivíduo saudável, numa referência ao conceito de figura e fundo, é aquele que é capaz de reconhecer claramente o que é para ele, num dado momento, a figura dominante. Posteriormente, ele desenvolve a possibilidade de satisfazer sua necessidade, acarretando em sua dissolução. Por fim, com a resolução desta, a pessoa fica então livre para uma nova atividade física ou mental. Dessa forma, quando esses ciclos de reconhecimento, satisfação e disponibilidade fluem de forma contínua, pode-se afirmar, em Gestalt-terapia, que a pessoa goza de boa saúde (Ginger \& Ginger, 1995). Ou, de acordo com Perls (1969), estar saudável é gozar de um equilíbrio apropriado na coordenação de tudo o que se é.

O funcionamento saudável também pode ser entendido como a habilidade que o indivíduo tem para se relacionar com o ambiente de forma criativa, expressando e suprindo suas necessidades ao mesmo tempo em que mantém uma relação de respeito com o outro na sua individualidade (Frazão, 1999). Saúde é um processo de atualização conjunta entre mundo e indivíduo, no qual a pessoa transforma e dá significado aos elementos circundantes ao mesmo tempo em que, por meio da relação com estes, transforma a si mesma (Augras, 2004). Relacionar-se aqui é entendido como a capacidade de fazer contato, assim o propósito da psicoterapia é tornar o ser humano novamente capaz de contatos, livrando-o de formas cristalizadas de agir (Burow \& Scherpp, 1985).

A perturbação do contato se apresenta de variadas formas em cada estilo particular de ser. No caso da esquizofrenia, observa-se o predomínio de um pensamento autista e a tendência ao fechamento do indivíduo em si mesmo, que procura isolar-se dos outros (Romero, 1997). Autismo aqui é entendido como a prevalência da vida interior e o desligamento voluntário do mundo exterior. No pensamento autista o indivíduo não confia, a priori, no mundo e em si próprio, restando apenas a perplexidade. Dessa forma qualquer ação humana fica comprometida, desde a mais complexa até a aparentemente mais simples, como o movimento, esse compreendido não apenas como deslocamento motor, mas ação que contém decisão, expressão e intenção. Esse quadro de esvaziamento descrito é o que se pode chamar autismo pobre (Tatossian, 2006).

Numa tentativa de manter sua essência humana, a pessoa esquizofrênica apresenta, para além do autismo pobre, o chamado autismo rico: maneiras de distanciamento do ambiente tais como o devaneio, o pesar, a interrogação e o racionalismo, este relacionado à perda do dinamismo vital (Tatossian, 2006).

De acordo com o Manual Diagnóstico e Estatístico de Transtornos Mentais - DSM-IV-TR, editado pela American Psychiatric Association (2003), uma pessoa é diagnosticada como esquizofrênica quando apresenta um misto de sinais e sintomas característicos, positivos ou negativos, por um período de tempo significativo durante um mês, com a persistência de alguns sinais por pelo menos seis meses. Por sintomas positivos entende-se a presença de delírios, alucinações, discurso desorganizado e comportamento amplamente desordenado ou catatônico. Em relação aos sintomas negativos pode-se citar a diminuição da afetividade, a alogia (incapacidade de falar) e a abulia (falta de desejo).

Para Barlow \& Duran (2008), a esquizofrenia é um transtorno que envolve comportamento psicótico. De acordo com estes autores o termo psicótico tem sido empregado para caracterizar muitos comportamentos incomuns, mais particularmente os delírios, conceituados como crenças irracionais e as alucinações: percepções sensoriais na ausência de eventos externos. Apresenta-se como uma visão alternativa o diagnóstico colaborativo e interventivo, que busca compreender o cliente por meio da ação conjunta da díade terapêutica. Esta compreensão consiste em verificar como a pessoa está num dado momento e o que ela poderá vir a ser. Trata-se de um exercício por si só terapêutico, por fazer com que o cliente entre em contato com suas vivências (Pimentel, 2003).

Para que o diagnóstico seja útil à compreensão da complexidade, dinâmica e singularidade do psiquismo de uma pessoa, é preciso que ele expresse o que há de particular em sua existência. É necessário que o diagnóstico esteja vinculado não a uma doença, mas ao modo de existir de um ser humano (Frazão, 1999). Isso se torna imperativo ao compreendermos a psicopatologia como uma tentativa de diálogo que não obteve resposta. Cabe ao psicoterapeuta compreender o que o problema do diagnóstico está dizendo a respeito da existência daquela pessoa, dando assim continuidade ao diálogo interrompido e contribuindo com a integração desse aspecto da vida de quem o procura (Hycner, 1995).

Nesse entendimento, o processo de diagnóstico, ou de padronização, já que no caso da Gestalt-terapia não há a busca por um rótulo específico, pode ser associado à criação artística. A semelhança é que ele exige aptidões não só cognitivas, mas também perceptivas e intuitivas em interação com os materiais disponibilizados pelo ambiente e com as exigências dele provenientes (Fagan, 1980). 
Partindo dessa percepção, este artigo propõe uma reflexão a respeito da forma como o encontro, nas suas dimensões técnica e artística, possibilita ao terapeuta-estagiário, numa perspectiva fenomenológica, compreender e cuidar do modo de ser de seu cliente diagnosticado como esquizofrênico. A escolha da temática aqui apresentada se dá pela inquietação do terapeuta-estagiário a respeito das possibilidades de atuação do psicólogo, baseado na Gestalt-terapia, frente às formas de sofrimento psíquico normalmente estigmatizadas como intratáveis pela Psicologia.

\section{Participante}

Possibilitou o desenvolvimento deste trabalho a participação de um cliente do sexo masculino, que aqui receberá o nome fictício de Adriano. Ele tem 26 anos, é solteiro, tem o ensino médio completo, estuda música e reside nesta capital com a mãe e as duas irmãs. Adriano ouve vozes na ausência de pessoas que as possam produzir e, embora isso aconteça desde sua infância, se intensificaram posteriormente. Devido a esse sintoma, desde os 18 anos faz tratamento psiquiátrico, tendo usado inicialmente o medicamento Olanzapina e atualmente Risperidona (não soube precisar a dosagem das drogas). O cliente não percebe melhoras com o tratamento medicamentoso, afirma apenas que os remédios o deixaram bastante sonolento e talvez assim tenham evitado que ele ficasse mais doido.

O início de seu tratamento psicológico se deu no segundo semestre de 2009, ocasião em que foi atendido por um terapeuta-estagiário do Centro Estudos, Pesquisa e Prática Psicológica - CEPSI, na perspectiva psicanalítica.

\section{Material}

Todos os atendimentos foram conduzidos no mesmo consultório do CEPSI, equipado com duas poltronas e uma mesa de centro, um tapete, almofadas, uma mesa de consultório com três cadeiras e um aparelho de ar condicionado. Foi utilizado também o Termo de Consentimento Livre e Esclarecido, um gravador digital, prancheta com papel e caneta para anotações e um relógio para controle do tempo das sessões.

\section{Procedimento}

Os atendimentos aconteceram uma vez por semana, com duração de 50 minutos cada, no período de agosto a dezembro de 2010, totalizando 15 sessões. Ao iniciar a primeira sessão, sabendo que, no semestre anterior, o cliente já havia sido atendido por outro estagiário do CEPSI, o terapeuta-estagiário retomou o contrato anteriormente firmado. Para isso o Termo de Consentimento Livre e Esclarecido foi utilizado como roteiro.

\section{Discussão}

Visando ilustrar a relação entre o apanhado teórico e as vivências possibilitadas pelo encontro entre cliente e terapeuta-estagiário, foram selecionados alguns recortes de sessões, expostos a seguir. Para sinalizar as falas do cliente e do terapeuta-estagiário serão utilizadas as letras $\mathrm{C}$ e $\mathrm{T}$, respectivamente.

\subsection{Primeira sessão}

No início da sessão, o terapeuta-estagiário explicita a forma como os atendimentos serão conduzidos, experienciando ir além do diagnóstico registrado:

T: (...) embora eu tenha algumas informações aqui (no prontuário) eu acho mais interessante ouvir de vocêo que tem como demanda, o que você acha importante trazer para a terapia e qual é a sua expectativa em relação à terapia.

Ao preferir escutar a demanda do cliente em detrimento do diagnóstico documentado, o terapeuta-estagiário apóia-se no entendimento de que o lugar principal na descrição fenomenológica é ocupado por aquilo que é central para a pessoa, não o que seria central para uma determinada psicopatologia (Dusen, 1975). Neste sentido, ao dar ênfase à experiência direta do indivíduo, o terapeuta-estagiário valoriza a capacidade do cliente de ser responsável pela própria existência (Ribeiro, 1985).

No fragmento a seguir, o cliente fala sobre a comunicação que tem estabelecido com as vozes que ouve. Ele tem a percepção de que a resposta que dá às vozes nem sempre é dele próprio, sentindo como se algo o manipulasse e respondesse por meio de sua boca. Adriano reconhece que suas percepções auditivas acontecem na ausência de eventos externos. Partindo-se da compreensão expressa pelo cliente quanto à ausência de elementos externos que desencadeiem os sons por ele ouvidos, pode-se inferir a existência de alucianações, que podem ser consideradas, de acordo com Barlow \& Duran (2008), componentes do comportamento psicótico característico da esquizofrenia.

C: (...) mas de um tempo para cá eu comecei a perceber que parece que não é eu que dou a resposta, é como se fosse eu mas não sou eu...

T: Ahan

C: As vezes eu chego a pensar que sou apenas uma carne e osso assim ó (gesticula representando um fantoche), 


\section{T: Hmm...}

C: que ando, sei fazer poucas coisas, quase nada, e só isso, como se eu fosse um fantoche assim ó que pessoa ficasse me levando, aí me virava para um lado, para outro alguma coisa assim...

Ao dar retornos ao cliente (Ahan, Hmm), o terapeuta-estagiário exercita um aspecto da escuta fenomenológica, que, quando efetivamente ocorre, permite ao fenômeno falar por si só (Romero, 1997). Partindo-se do entendimento de que a psicopatologia é uma tentativa de dialogar que ficou sem resposta (Hycner, 1995), é pertinente observar essa intervenção do terapeuta-estagiário como favorecedora da continuidade deste diálogo, por meio da escuta.

\section{T: Você percebe isso agora?}

C: Comecei a perceber de uns tempos para cá...

T: E nesse momento aqui e agora você percebe isso?

C: (pausa) olha, agora não, agora parece que é eu que to falando, mas se outra hora que eu paro para analisar essa situação parece que, sei lá, parece que eu tenho a impressão que não fui, que não era eu que tava conversando...

É utilizada a experiência vivida no decorrer da sessão como oportunidade de promover a ampliação da awareness do cliente, já que esta é um ato que acontece sempre aqui-e-agora (Yontef, 1998). Esta intervenção fundamenta-se nas propostas gestaltista e existencialista, que dão ênfase à liberdade e responsabilidade do homem, concebido como capaz de estar cada vez mais consciente de si próprio a partir da experiência vivida no agora (Ribeiro, 1985).

C: eu vou na igreja, na igreja falam sobre o sobrenatural e eu percebo alguma coisa sobrenatural, mas como eu vou provar? (...) eu vou na igreja protestante e sei lá, a igreja protestante tem umas coisas muito estranhas, (...) de repente tinha um pessoal falando em línguas estranhas, uma coisa bem ilusória, como se estivessem todos iludidos, (...) e eles pulavam assim e falavam (...) e batiam palmas... não sei se você já foi em igreja protestante...

T: Já fui, já presenciei isso...

Ao defrontar-se com a semelhança entre a experiência que seu cliente apresentou e suas próprias vivências, o terapeuta-estagiário optou por compartilhar seu vivido. Esta atitude remete ao que Ginger \& Ginger (1995) dizem a respeito do trabalho do terapeuta, que demanda não só a utilização do que o profissional sabe, mas também, na mesma proporção, daquilo que ele é. Ademais, nessa intervenção o terapeuta-estagiário demonstra estar presente, uma vez que a presença é entendida como o reconhecimento da permeabilidade da existência humana, algo que ultrapassa a técnica. No contexto da psicoterapia ela pode ser expressa por meio da disponibilidade por parte do terapeuta em contribuir com seu próprio eu para o encontro (Hycner, 1995).

C: então, aquilo ali é uma coisa muito estranha, depois eu peguei um negócio que os teólogos e eles falaram que tem muitas pessoas que estão lá movidas por uma coisa que eles pensam que é espírito santo mas não é. T: E para você é o que?

O questionamento feito pelo terapeuta-estagiário visa tornar o cliente mais consciente do seu papel ativo, enquanto ser livre para construir o mundo, pela atribuição de significados (Forghieri, 2004). Dessa forma, mais importante que discorrer a respeito das possíveis entidades que podem mobilizar as pessoas, é estimular o cliente a fazer contato com a forma como sua consciência intenciona o mundo.

\section{C: Para mim não pode ser nada por que eu não tenho teoria, eu não tenho embasamento para explicar nada, para mim pode ser qualquer coisa eu não sei qual qual é a verdade eu vivo em busca da verdade mas qual é a verdade em várias histórias que se passam na minha cabeça eu não sei qual é então eu simplesmente não estou querendo nem pensar quando vem uma questão na minha cabeça eu não quero nem tentar resolver ela, procurar uma forma de resolver ela, eu deixo para lá...}

O cliente demonstra nos constantes questionamentos, neste encontro sintetizados por eu vivo em busca da verdade, uma atitude de recuo em relação ao ambiente, característica do chamado autismo rico (Tatossian, 2006). Aqui também é expressa sua forma de se autorregular, que tem passado por deixar de lado as perguntas para as quais não tem uma resposta verdadeira. Entende-se por autorregulação o processo pelo qual o organismo interage na busca da manutenção da homeostase; por sua vez, homeostase é definida como um estado de equilíbrio que é sempre dinâmico (Cardella, 2002). Neste modo particular de equilibrar-se é perceptível o pensamento característico do autismo pobre, descrito por Tatossian (2006), que manifesta a ausência da conivência pré-reflexiva com o mundo e consigo mesmo, que os tornariam confiáveis e conhecidos antes de serem reconhecidos intelectualmente.

Em relação à atitude terapêutica, após esta última frase do cliente é feito o exercício da suspensão de juízos a priori, que para Ribeiro (1985) é um componente da atitude fenomenológica que possibilita a percepção da realidade tal como ela se apresenta. Nesta situação, ao perguntar " $E$ para você o que é?" o terapeuta-estagiário conta com uma resposta menos intelectualizada, mas tem de suspender suas expectativa e frustração para então continuar escutando o que o cliente diz. 


\subsection{Segunda sessão}

C: (...) Não ando me importando para quase nada. Ah, a vida não tem muita graça na terra não. A vida na terra é sofrimento, o povo que nasceu na terra nasceu para sofrer, pegando a maioria como exemplo.

T: Sim...

C: Nasceu para se arrebentar de trabalhar e não conseguir nada, querer uma coisa e não conseguir, não satisfazer seus desejos, não satisfazer nada e morrer achando que foi feliz. Tava vendo café filosófico esses dias, a mulher tava falando que para você dar um pouquinho de sentido para sua vida primeiro você tem que descobrir que a vida não tem sentido (...).

T: Certo.

C: Ela tava falando sobre essa parte da vida aí, se a vida tem sentido ou não tem sentido. Aí eu lembro bem a hora que ela falou: "a vida na terra, para você dar um pouco de sentido para ela, primeiro você tem que descobrir que ela não tem sentido, que ela perdeu o sentido, ela perdeu”. Aí eu já tinha pensado isso antes dela falar..

T: Aham

C: o negócio meu é que na filosofia as idéias batem mais do que na igreja...

T: Nossa, que bom que você está percebendo que tem um lugar onde as idéias batem mais..

Ao valorizar a percepção do cliente, o terapeuta-estagiário busca torná-lo mais aware em relação às suas preferências e capacidade perceptiva. $\mathrm{Na}$ fala a respeito de como percebe a compatibilidade de suas idéias com a igreja e com a filosofia, o cliente tem a chance tomar consciência da própria intencionalidade, assim, de acordo com Ribeiro (1985), de ampliar sua awareness.

Essa tomada de consciência vai além da situação em questão, refletindo-se em outros aspectos da vivência do cliente. Isso porque, como afirmam Lima (2005) e Perls (1988), numa percepção integrada de homem, qualquer que seja a alteração que o organismo sofra, ela se refletirá na sua totalidade. Nesta compreensão, há aqui uma tentativa de possibilitar a ampliação perceptual de Adriano a respeito do que mais lhe agrada, para além do que foi por ele verbalizado, estendendo-se para outros âmbitos da sua vida e podendo assim torná-lo mais capaz de fazer escolhas conscientes.

C: Bate mais que na igreja, porque na igreja parece que tem um domínio, eu sinto assim meio que uma imposição, uma imposição de você não poder questionar, de você não poder..

T: Qual é a sensação de não poder questionar?

C: Ela é ruim. (...) A filosofia permite muito que você questione (...)

T: Aham..
C: E uma das formas de adquirir conhecimento é através das questões, questionar tudo.

T: Você tem este tipo de conhecimento questionando?

Por meio deste questionamento, o terapeuta-estagiário busca trazer o cliente para o contato com o seu vivido. Esta intervenção justifica-se pelo fato de que a dimensão concreta, numa visão existencialista, é um aspecto humano que precede a abstração (Ginger \& Ginger, 1995).

C: Não porque eu não tenho muitas pessoas para me responder, não tenho uma fonte de resposta, eu tenho só fonte de questionamento. Aí quando eu vou para a filosofia eu encontro as respostas, quando eu vejo café filosófico (...).

T: Então para ter conhecimento além de fazer as perguntas você precisa de uma fonte de respostas, você reconhece que não tem muitas fontes de respostas, mas você já está reconhecendo algumas, você disse que tem o café filosófico por exemplo...

C: Poucas coisas mas tem, tem.

T: Aham... Nossa, que bom que tem lugar para buscar as respostas então...

Ao valorizar o há de positivo o terapeuta-estagiário busca levar seu cliente a fazer contato com os elementos que estão à sua disposição. Entende-se que o propósito da psicoterapia é tornar o ser humano novamente capaz de contatos, possibilitando assim a diversificação do seu agir (Burow \& Scherpp, 1985).

\subsection{Oitava sessão}

Esta sessão tem a duração excepcional de 1h34, ao invés dos costumeiros 50 minutos. O prolongamento é motivado pela emergência de conteúdos que mobilizam a díade terapêutica, optando o terapeuta-estagiário, com base numa perspectiva dialógica, por valorizar o que está acontecendo na esfera do entre. Subsidia esta atitude o que dizem Hycner (1995) e Hycner \& Jacobs (1997), a respeito da dimensão do entre, também chamada inter-humano: é nela que reside a possibilidade de um encontro facilitador do processo de cura.

C: Ontem eu saí, vou começar a fazer exercício físico agora, pegar uma massa muscular (...) meu pai nem para falar isso para mim (da necessidade dos exercícios físicos), nem minha mãe (...) eu não sei como eu não percebi (...).

O cliente traz como figura a percepção do próprio corpo. A considerar que outros temas repetidos nas sessões anteriores deram lugar a este, que até então não havia emergido, pode-se dizer que há, neste momento, uma demonstração de saúde. Isto porque, conforme Ginger \& 
Ginger (1995), uma das etapas do funcionamento saudável é o reconhecimento da figura dominante, seguido do desenvolvimento de uma forma de satisfação e finalmente de sua dissolução. Pode-se dizer que houve a dissolução, ao menos temporária, das figuras eleitas em outras sessões para que se tornasse possível a emergência desta nova. Assim, verifica-se o fluir dos ciclos de reconhecimento, satisfação e disponibilidade característicos do existir saudável.

T: Agora você começou a fazer (exercícios físicos), de onde é que veio essa percepção (da necessidade de ganho de massa muscular)?

C: Eu mesmo percebi, olhei para o meu braço olha aqui ó (...) não pode, olha o meu tamanho...

T: Entendo... Acho interessante que ninguém disse e você percebeu né...

C: Então, eu tenho que aprender sozinho, eu tenho que aprender as coisas sozinho porque as pessoas não fala nada para mim não, parece que eu fico aí se eu não perceber as coisas...

T: Essa coisa você conseguiu sozinho, você conseguiu perceber sozinho que precisava ganhar massa e agora você está fazendo algo para isso.

A fala acima mostra um exercício proposto pela Gestalt-terapia, o de procurar o que há de positivo na pessoa e a partir daí conferir ênfase à sua capacidade criativa em relação ao próprio existir. Para tanto é estabelecido o contato com seu potencial de vida: o que ela tem de forte, belo e saudável (Ribeiro, 1985). Corrobora esta intervenção a afirmação de Pimentel (2003), de que entrar em contato com as próprias vivências por si só é terapêutico.

A respeito da atitude verbalizada pelo cliente, de se perceber numa situação indesejável e procurar mecanismos para contorná-la, é perceptível o que Frazão (1999) cita como inerente ao funcionamento saudável: a capacidade de relacionar-se com o ambiente de forma criativa, expressando e suprindo suas necessidades.

C: Não contei a outra parte da história, essa história eu não conto para quase ninguém. Assim que cheguei em Goiânia (...) a polícia veio, socando minha barriga e perguntando onde tava o bagulho (...) como não encontraram nada comigo, me levaram. Acusação: estupro (...) sem ter feito nada fiquei do meio do ano de 2002 até 2009 em audiência de "duque 13" (...) sabendo que não tinha feito nada, fiquei na delegacia da mulher de segunda a sexta-feira detido (...) só que era muito fácil, muito bom se o cara tivesse deixado esperma nela (na vítima), se tivesse esperma ia ver que não era eu... T: Certo.

C: Eu já ouvia vozes nessa época... Tinha que provar que não fui eu... Essa mulher, ela nunca apareceu, até as delegações finais do processo. Era a minha palavra contra a dela (...). Diz o policial que foi na audiência, que ela estava transtornada no dia do reconhecimento. O fato tinha acontecido 20 dias antes, no dia em que ela foi estuprada eu estava na casa do meu primo. O mesmo estuprador atacou outra pessoa quando eu estava preso na delegacia da mulher (...)

T: Você contou essa história para poucas pessoas, eu me sinto privilegiado. Você teve que superar uma coisa muito difícil...

C: Quando o cara fez, ele tem na mente dele "oh fiz aquele dia agora olha o que está acontecendo comigo agora”. Agora eu lá na história não ia pensar isso, ia pensar "não fiz nada e estou aqui nessa miséria". Com certeza eu ia por a culpa em Deus lá, ixe com certeza, até na época do duque 13 para mim a culpa era de Deus, eu não tinha outro culpado na minha cabeça não, eu ia na igreja mas para mim a culpa era de Deus, para mim o culpado naquela época era Deus... T: E agora parece que você deu outro significado para esta situação...

C: Agora eu nem penso mais nisso (...) foi um processo longo, cada intimação demorava meio ano a cada intimação, meio ano, imagina você viver aí dos 18 até quase 26 anos pensando assim ó amanhã posso estar lá no cadeião e sem ter feito nada...

O terapeuta-estagiário busca escutar seu cliente com uma postura de aceitação, ciente de que a ajuda se torna possível quando o encontro é baseado numa relação de igualdade (Feldman, 2006). Isto significa vivenciar o fato de que tanto ele quanto seu cliente estão na mesma condição humana, a de busca pela integridade, pelo fortalecimento da capacidade individual em seguir rumo à harmonia (Ribeiro, 1985). Neste contexto é exigida do terapeuta não apenas a utilização de seu conhecimento técnico a serviço da condução da psicoterapia e, consequentemente, da catalisação do processo positivo de transformação, mas também a mobilização de seus recursos pessoais (Fagan, 1980). Hycner (1995) denomina essa disponibilidade como presença-distanciada, o ato de estar presente ao passo que também há o exercício da reflexão a respeito do que está sendo vivido.

\section{Considerações Finais}

No intento de facilitar o processo de saúde existencial de uma pessoa diagnosticada como esquizofrênica, o terapeuta-estagiário tem como primeira tarefa a compreensão da esquizofrenia como um modo de ser, um fenômeno relacionado a um contexto e que não pode ser visto simplesmente como uma doença, ou seja, algo individual. Ginger \& Ginger (1995) sustentam esta compreensão ao considerarem que qualquer fenômeno não é uma realidade em si, mas inter-relação entre ele próprio e o meio que o circunda momentaneamente. Complementam este entendimento Delisle (1999) e Perls (1988), ao afirmarem 
que qualquer experiência humana só acontece no campo organismo-meio.

Para compreender as vivências compartilhadas em cada encontro é utilizada, sobretudo, a perspectiva fenomenológica, além do próprio ser do terapeuta-estagiário, que fica o máximo possível disponível para o cliente. Assim, arte e técnica se complementam. A esse respeito, Hycner (1995) afirma que o aspecto mais exigente da profissão de psicoterapeuta é a integração entre a arte e a ciência da psicoterapia, assinalando que a negligência de um destes fatores acarretará em prejuízo à pessoa que procura ajuda.

Contudo, em algumas situações, o terapeuta-estagiário se vê diante da escolha de uma dessas polaridades. Quando isso ocorre, opta-se pela arte, ou seja, pela disponibilidade do próprio ser do terapeuta-estagiário, que coloca-se presente, despido de técnicas, na dimensão do entre. De acordo com Hycner (1995), citando Buber, é na esfera do entre onde reside a possibilidade de cura da pessoa que enfrenta conflitos no relacionamento com os outros; ou, de outro modo, com o mundo dos outros. Assim, quando, por exemplo, a duração de uma das sessões é extrapolada, o terapeuta-estagiário opta por permanecer em relação com seu cliente, mesmo em detrimento da duração cronológica que seria esperada para o atendimento. Essa forma de estar com alguém, desinteressada por qualquer objetividade, é o que Buber (1974) denomina experiência Eu-Tu.

Adriano expressa o desejo de ressignificar-se que, combinado com a disponibilidade para o encontro, torna possível o caminhar do seu processo de saúde existencial. O que é considerado saúde existencial está relacionado com a denominação de Forghieri (2004), pois, quando o cliente vivencia algo novo, ele está demonstrando melhora na sua capacidade de lidar com a amplitude e as restrições da existência. Eleger figuras novas é uma forma de vivenciar a amplitude do existir.

Ademais, Adriano compartilha de um aspecto da sua história do qual declara falar com reservas. Assim, ainda a respeito da saúde, entendida por Augras (2004) como um processo de atualização, pela ressignificação dos e com os elementos circundantes e por Burow \& Scherpp (1985) como a capacidade de fazer contato, pode-se dizer que Adriano torna-se mais saudável ao se atualizar por meio do contato que faz com a releitura de sua história.

\section{Referências}

American Psychiatric Association (2003). Manual diagnóstico e estatístico de transtornos mentais ( $4^{\mathrm{a}} \mathrm{Ed}$.). Washington, DC: Autor.

Augras, M. (2004). O Ser da Compreensão: Fenomenologia da Situação de Psicodiagnóstico. (11ª Ed.). Petrópolis: Vozes.
Barlow, D. H., \& Durand, V. M. (2008). Psicopatologia: uma abordagem integrada (Tradução da 4 a edição norte-americana). São Paulo: Cengage Learning.

Burow, O., \& Scherpp, K. (1985). Gestaltpedagogia: um caminho para a escola e a educação (L. A. Lilienthal, trad.). São Paulo: Summus.

Buber, M. (1974). Eu e Tu (Tradução do original alemão Ich und Du, 8a edição, Lambert Schneider, Heidelberg, 1974). São Paulo: Centauro Editora.

Cardella, B. H. P. (2002). A construção do psicoterapeuta - uma abordagem gestáltica. São Paulo: Summus.

Delisle, G. (1999). As Relações Objetais na Gestalt-terapia: Em Direção a uma Abordagem Integrada para o Tratamento dos Distúrbios de Personalidade. Revista do V Encontro Goiano da Abordagem Gestáltica: Humanizando o Diagnóstico, $5,45-62$.

Dusen, W. V. (1975). A Fenomenologia de Uma Existência Esquizofrênica. Em J. O. Stevens (Org.), Isto é gestalt (p. 133-153). São Paulo: Summus. (Trabalho original publicado em 1961).

Fagan, J. (1980). As Tarefas do Terapeuta. Em J. Fagan \& I. L. Shepherd (Orgs.), Gestalt-Terapia: Teoria, Técnicas e Aplicações (p. 123-148). Rio de Janeiro: Zahar Editores.

Feldman, C. (2006). Encontro: uma abordagem humanista (3 ${ }^{\mathrm{a}}$ ed.) Belo Horizonte: Crescer.

Forghieri, Y. C. (2004). Psicologia Fenomenológica: fundamentos, métodos e pesquisa. São Paulo: Pioneira Thomson Learning

Frazão, L. M. (1999). Compreensão do Funcionamento Saudável e Não Saudável - A Serviço do Pensamento Diagnóstico em Psicoterapia. Revista do V Encontro Goiano da Abordagem Gestáltica: Humanizando o Diagnóstico, 5, 27-33.

Ginger, S. \& Ginger, A. (1995). Gestalt: uma terapia do contato. São Paulo: Summus.

Hycner, R. (1995). De pessoa a pessoa: psicoterapia dialógica. São Paulo: Summus.

Hycner, R. \& Jacobs, L. (1997). Relação e Cura em Gestalt-terapia. São Paulo: Summus.

Lima, P. (2005). Teoria organísmica. IGT na Rede, 2.3. Retirado de http://www.igt.psc.br/revistas/seer/ojs/viewarticle. php?id=57.

Perls, F. (1969). Gestalt-Terapia Explicada. Rio de Janeiro: Summus.

Perls, F. (1988). A Abordagem Gestáltica E Testemunha Ocular da Terapia. Rio de Janeiro: LTC.

Petrelli, R. (1999). Humanizando o Psicodiagnóstico. Revista do VEncontro Goiano da Abordagem Gestáltica: Humanizando o Diagnóstico, 5, 23-25.

Pimentel, A. (2003). Psicodiagnóstico em Gestalt-terapia. São Paulo: Summus.

Polster, M., \& Polster, E. (2001). Gestalt-Terapia Integrada. São Paulo: Summus. 
Ribeiro, J. P. (1985). Gestalt-terapia: refazendo um caminho. São Paulo: Summus.

Ribeiro, J. P. (2006) Vade-mécum de Gestalt-terapia: conceitos básicos. São Paulo: Summus.

Romero, E. (1997). O Inquilino do Imaginário: Formas de Alienação em Psicopatologia. São Paulo: Lemos Editorial.

Tatossian, A. (2006). A alienação esquizofrênica. Em: Tatossian, A., Fenomenologia das Psicoses. (p. 57-95). São Paulo: Escuta.

Yontef, G. M. (1998). Processo, diálogo e awareness: ensaios em Gestalt-terapia. São Paulo: Summus.

Júlio Manoel dos Santos Filho - Graduado em Psicologia pela PUC Goiás. Aluno do Mestrado em Psicologia da UFG. Atua como Psicólogo no Instituto Federal de Educação, Ciência e Tecnologia de Goiás (IFG).

E-mail: juliomsfilho@gmail.com

Virgínia Elizabeth Suassuna Martins Costa - Psicóloga Clínica, Doutora em Ciências da Saúde pela UnB/UFG, Professora-Adjunta do curso de Psicologia da Pontifícia Universidade Católica de Goiás (PUC-GO). E-mail: virginia@itgt.com.br

Recebido em 16.09.2014 Primeira Decisão Editorial em 17.09.2015 Aceito em 07.04.2016 